\title{
Determination of Antioxidant Activity of Caffeic Acid and $p$ - Coumaric Acid by Using Electrochemical and Spectrophotometric Assays
}

\author{
Anna Masek ${ }^{1, *}$, Ewa Chrzescijanska ${ }^{2}$, Malgorzata Latos ${ }^{1}$ \\ ${ }^{1}$ Technical University of Lodz, Institute of Polymer and Dye Technology, Faculty of Chemistry, 90- \\ 924 Lodz, ul. Stefanowskiego 12/16, Poland \\ ${ }^{2}$ Technical University of Lodz, Institute of General and Ecological Chemistry, Faculty of Chemistry, \\ 90-924 Lodz, ul. Zeromskiego 116, Poland \\ "E-mail: anna.masek@p.lodz.pl
}

doi: $10.20964 / 2016.12 .73$

Received: 18 August 2016 / Accepted: 20 September 2016 / Published: 10 November 2016

\begin{abstract}
The aim of our study was to investigate the mechanisms of electrooxidation selected hydroxycinnamic acids. The curves made on the basis of cyclic and differential pulse voltammetry and quantum chemical calculations were given the opportunity to determine the scheme of oxidation of the molecule caffeic acid. The described scheme shows, that caffeic acid changes two electrons in the first stage of electrooxidation and for $p$-coumaric acid is exchanged one electron. It was determined the antioxidant potential of the tested compounds using spectrophotometric methods such as: ABTS, DPPH, FRAP and CUPRAC. Both caffeic acid and $p$-coumaric acid were characterized by a high capacity for scavenging free radicals as well as the reduction of iron and copper ions. However, caffeic acid exhibited improved antioxidant properties, which increase linearly as a function of their concentration. Definitely, however, caffeic acid was a lot stronger reducing agent in the oxidation processes.
\end{abstract}

Keywords: electrooxidation; antioxidant; spectrophotometric assay, caffeic acid, $p$-coumaric acid

\section{$\underline{\text { FULL TEXT }}$}

(C) 2016 The Authors. Published by ESG (www.electrochemsci.org ). This article is an open access article distributed under the terms and conditions of the Creative Commons Attribution license (http://creativecommons.org/licenses/by/4.0/). 